\title{
O Aspecto nas construções infinitivas e gerundivas complementos de verbos de percepção
}

\author{
L'Aspect dans les constructions infinitives et gérondives \\ compléments des verbes de perception
}

\section{Patrícia de Araujo Rodrigues}

PUCPR

\section{Résumé}

Dans ce travail, nous examinons la structure temporelle des compléments des verbes de perception construits avec l'infinitif ( $E u$ vi a Maria chorar) et avec le gérondif (Eu vi a Maria chorando), en portugais brésilien. Nous argumentons que la structure de ces compléments correspond à la projection AspP, obtenue comme résultat de l'interaction entre l'aspect lexical, lié à la structure événementielle du prédicat (qui doit tenir compte, entre autres, du type sémantique du prédicat - individual-level ou stage-level), et l'aspect grammatical. Cette structure permet d'expliquer certaines des propriétés sémantiques des constructions étudiées, telles que l'interprétation directe du verbe de perception, la restriction aux prédicats individual-level, la dépendance temporelle de la subordonnée par rapport à la matrice et les différences aspectuelles observées entre les compléments infinitifs et gérondifs.

Mots-clés

verbes de perception, infinitif, gérondif, aspect. 


\section{Resumo}

Este trabalho propõe-se a examinar a estrutura temporal dos complementos dos verbos de percepção construídos com o infinitivo (Eu vi a Maria chorar) e com o gerúndio (Eu vi a Maria chorando), em português brasileiro (PB). Argumenta-se que a estrutura desses complementos corresponde à projeção AspP, obtida como resultado da interação entre o aspecto lexical, ligado à estrutura de evento do predicado (que deve levar em conta, entre outros, o tipo semântico do predicado - individual-level ou stage-level), e o aspecto gramatical. A estrutura proposta permite explicar as propriedades semânticas das construções estudadas, tais como a interpretação direta do verbo de percepção, a restrição aos predicados individual-level, a dependência temporal da encaixada com relação à principal e as diferenças aspectuais existentes entre os complementos infinitivos e gerundivos.

\section{Palavras-chave}

verbos de percepção, infinitivo, gerúndio, aspecto. 


\section{INTRODUÇÃO}

objetivo deste trabalho é discutir as propriedades aspectuais e temporais de dois tipos de complementos dos verbos de percepção não-agentivos ${ }^{1}$, os complementos infinitivos (1a) e os complementos gerundivos (1b), analisados como constituintes únicos ${ }^{2}$.
(1) a Eu vi a Maria chorar.
b Eu vi a Maria chorando

De forma geral, os complementos infinitivos e gerundivos possuem propriedades semânticas semelhantes: i) eles apresentam uma dependência temporal com relação à oração principal (2), o que implica a interpretação direta do verbo de percepção e a simultaneidade entre o evento da percepção e o evento percebido ${ }^{3}$; ii) são incompatíveis com predicados individual-level (3).

(2) a *Ontem, eu vi o João beijar a Maria antes de ontem.

b *Ontem, eu vi o João beijando a Maria antes de ontem.

(3) a *Nós vimos o João saber a lição.

b *Nós vimos o João sabendo a lição.

Essas propriedades caracterizam também os complementos infinitivos e gerundivos dos verbos de percepção em inglês (4).

(4) a *Yesterday, I saw John kiss / kissing Mary the day before.

b *We saw him know / knowing the answer. (BOIVIN, 1998, p. 108.)

(FELSER, 1999, p. 74.)

Autores como Declerck (1981) e Felser (1999) afirmam que esses complementos apresentam, contudo, uma diferença aspectual, a saber, o 
complemento gerundivo descreve o evento percebido como uma ação incompleta, enquanto o complemento infinitivo implica normalmente que o evento descrito foi observado em sua totalidade.

Neste trabalho, nos propomo-nos a examinar os complementos infinitivos e gerundivos dos verbos de percepção em PB, com o objetivo de explicar as propriedades observadas com relação à restrição aos PILs e à dependência temporal do complemento e de verificar se a diferença aspectual existente entre esses complementos pode ser definida como proposto por Declerck (1981) e por Felser (1999).

Para tanto, discutiremos em primeiro lugar a análise de Felser (1999) relativa aos complementos não finitos do inglês. Essa autora propõe que esses complementos são uma projeção da categoria funcional Aspecto, que carrega o traço [+prog] no caso dos complementos gerundivos e [-prog] no caso dos complementos infinitivos. Para Felser, que adota a hipótese de Kratzer (1995) de que os predicados stage-level (PSL) possuem um argumento Evento ausente dos PIL, somente os PSLs projetam AspP (a realização sintática de um evento), enquanto os PILs projetam TP (a realização sintática de uma proposição). Essa análise explicaria a nãoocorrência de PILs como complementos de verbos de percepção com interpretação direta, que selecionam semanticamente um evento.

Da mesma forma que Felser, defendemos a hipótese de que a estrutura desses complementos em $\mathrm{PB}$ corresponde à projeção AspP e adotamos a distinção entre PILs e PSLs em termos da ausência/presença do argumento evento. Discordamos de Felser, no entanto, quanto à realização sintática desses predicados. Sustentamos que Asp é sempre projetado na estrutura dos complementos não finitos e que o valor aspectual associado à oração é resultado da interação entre o aspecto lexical, ligado à estrutura de evento do predicado (que deve levar em conta, entre outros, o tipo semântico do predicado - individual-level ou stage-level), e o aspecto gramatical. Também discordamos de Felser com relação à identificação do aspecto do complemento infinitivo como "não progressivo". Defendemos que o complemento infinitivo, por não portar marcas morfológicas aspectuais, "herda" o valor aspectual do verbo de percepção. Com base em Ramchand (2004), propomos que Asp introduz uma variável temporal à qual cabe representar os diferentes aspectos do predicado e cujo valor pode ser 
modificado por operadores aspectuais, como o operador progressivo, ou pelo valor aspectual da matriz.

Na seção 2, apresentamos a análise de Felser para os complementos infinitivos e gerundivos do inglês. Em seguida, na seção 3, apresentamos a proposição de Ramchand (2004) para a estrutura temporal da frase. A seção 4 discute o papel do argumento evento na estrutura temporal da frase. A seção 5 discute os dados do PB e nossa proposição para a derivação da estrutura dos complementos infinitivos e gerundivos. Apresentamos nossas considerações finais na seção 6 .

\section{A ANÁLISE DE FELSER (1999)}

Felser (1999), em um estudo sobre os verbos de percepção em inglês, argumenta, seguindo Declerck (1981), que os complementos infinitivos e os complementos gerundivos dos verbos de percepção distinguem-se unicamente com relação ao seu valor aspectual, o gerúndio correspondendo à contrapartida progressiva do infinitivo. Para a autora, ainda que interpretações diferentes possam ser atribuídas à forma do progressivo, a função geral desta forma verbal é indicar que um evento está "em progresso". O progressivo marca uma situação contínua, em desenvolvimento ou incompleta. Assim, de acordo com Felser, o complemento gerundivo descreve o evento percebido como uma ação em progresso ou como incompleta, enquanto o complemento infinitivo implica normalmente que o evento descrito foi observado em sua totalidade. Essa diferença de interpretação, ilustrada pelos exemplos em (5), corresponderia à distinção entre o aspecto imperfectivo (progressivo) e o aspecto perfectivo (não progressivo).

(5) a I saw her drowning, but I rescued her. (FELSER, 1999, p. 77.)

b \#I saw her drown, but I rescued her.

Conforme Felser, a construção em (5b) é incoerente, porque o infinitivo implica uma ação que foi completada, enquanto a construção em (5a) é coerente, porque o gerúndio sugere que a ação está em desenvolvimento. A diferença entre essas duas construções seria a mesma observada entre as construções matrizes progressivas e não progressivas, exemplificadas em (6). 
(6) a She was drowning, but she was rescued. (FELSER, 1999, p. 77.)

b \#She drowned, but she was rescued.

Considerando que a única diferença entre os complementos infinitivos e os complementos gerundivos do inglês é aspectual, Felser propõe uma mesma estrutura para dar conta dessas construções. Com base no fato de que o inglês é marcado para o aspecto progressivo e supondo que o Aspecto pode ser considerado um núcleo sintático independente que atrai o verbo em um dado momento da derivação para verificação de seus traços aspectuais, essa autora propõe que os complementos infinitivos e gerundivos do inglês formam um constituinte único cujo núcleo é a categoria funcional Aspecto especificado para o traço $[ \pm$ prog]. Assim, a categoria Aspecto núcleo do complemento gerundivo possuiria um traço [+prog], enquanto a categoria Aspecto núcleo do complemento infinitivo possuiria um traço [-prog].

Para explicar a restrição com relação aos PILs, Felser adota a proposição de Kratzer (1995) segundo a qual somente os PSLs apresentam um argumento Evento, que deve ser considerado como preferencial em uma hierarquia temática. Dessa forma, ele deve realizar-se sintaticamente como um argumento externo e ocupar uma posição fora da projeção máxima de seu predicado. Felser sugere que os PSLs, ao contrário dos PILs, projetam um nódulo aspectual para abrigar o argumento Evento (em [Spec, AspP]). Essa proposição é baseada principalmente no fato de que a presença de um argumento Evento nos PSLs está em correlação com o fato de eles admitirem a forma do progressivo be + ing, enquanto a ausência de um argumento Evento nos PILs está em correlação com o fato de eles não aparecerem sob a forma progressiva. A estrutura em (7) representa as construções formadas por um PSL, e a estrutura em (8) representa as construções formadas por um PIL, segundo Felser. 
(7)

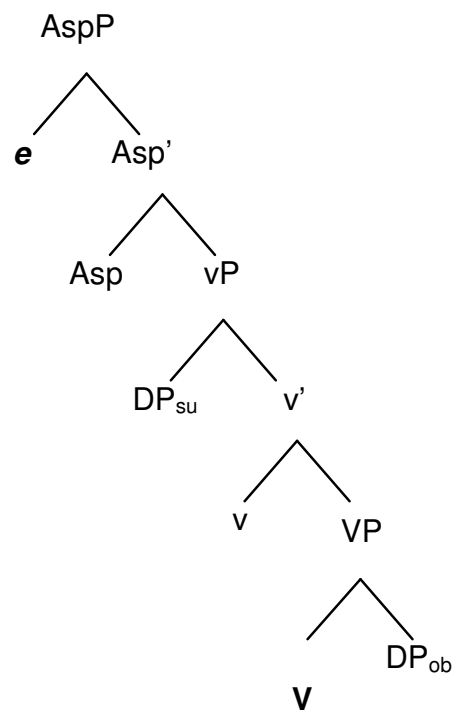

(8)

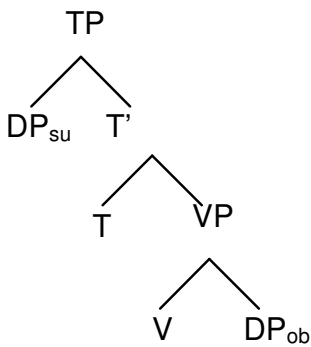

Na estrutura associada aos PSLs (7), [Spec, AspP] contém então o argumento Evento $e$, uma categoria vazia formalmente licenciada por Asp. Os PILs (8), que não possuem um argumento Evento e não projetam Asp, devem, necessariamente, projetar uma categoria mais alta, TP, para que seu DP sujeito possa ser gerado. Felser adota a estrutura $v P$-shell para os PSL transitivos e especifica que os PILs não projetam essa estrutura, porque não permitem um sujeito agentivo.

Felser assume que o argumento Evento é um argumento de tipo pronominal que deve ser identificado e propõe que ele deve receber um índice temporal de T. Nas orações finitas, a identificação desse argumento é obtida em uma configuração Spec-núcleo, com o alçamento do argumento em [Spec, TP]. Nesses casos, o argumento Evento é do tipo de pro (E-pro). Felser propõe que o argumento Evento que não pode ser identificado localmente em uma configuração [Spec, TP] é um argumento do tipo de PRO (E-PRO). Este seria o caso do argumento Evento dos complementos não finitos dos verbos de percepção constituídos de um PSL, dado que TP não é projetado em sua estrutura. Nessas construções, um único nódulo T, o da 
matriz, deve legitimar dois argumentos Evento distintos, o argumento Evento do verbo de percepção e o argumento Evento da encaixada. Felser sugere que o argumento Evento da matriz recebe um índice de T e que o argumento Evento da subordinada recebe seu índice temporal por meio do argumento Evento da matriz. O verbo de percepção funcionaria, assim, como um verbo de controle, como prometer, com a diferença de que a relação de controle se dá entre os argumentos Eventos E-pro e E-PRO e não entre um DP e um PRO. A estrutura em (9) representa a relação de percepção segundo a análise de Felser (1999, p. 146).

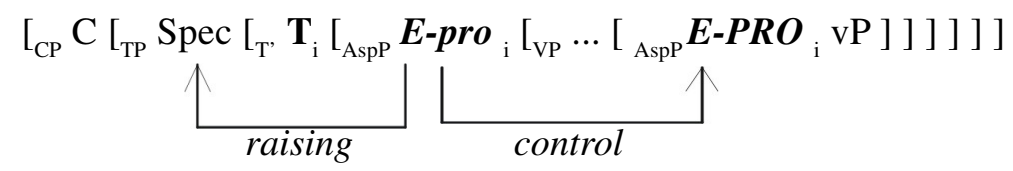

Para explicar a restrição aos PILs, Felser propõe que os verbos de percepção com interpretação direta selecionam semanticamente indivíduos, e não proposições, e que indivíduos podem ser realizados por meio de DPs ou AspPs. Assim, os complementos não finitos, cuja realização canônica é AspP, envolvem necessariamente PSLs. Os PILs, que não possuem um argumento Evento e que não projetam AspP, mas que projetam TP (realização de uma proposição), não seriam selecionados pelos verbos de percepção com interpretação direta. A percepção direta resultaria, então, do controle que o argumento Evento dos verbos de percepção (E-pro (ou seu vestígio)) exerce sobre o argumento Evento do complemento (E-PRO), o que acontece somente com os PSL, que possuem um argumento Evento gerado em [Spec, AspP].

Resumindo, para Felser, os verbos de percepção com interpretação direta selecionam semanticamente um indivíduo, que, no caso dos complementos infinitivos e dos complementos gerundivos, é realizado por meio de uma projeção AspP. A projeção de Asp só é possível quando o predicado é um PSL (que possui um argumento Evento), porque esse tipo de predicado admite a forma do progressivo be + ing. Os PILs, que não admitem a forma do progressivo, não projetam AspP, devendo projetar TP para que seu argumento externo - o argumento sujeito - possa ser realizado. A presença de $\mathrm{T}$ transforma o complemento em uma proposição, um tipo semântico que não é compatível com a percepção direta. Dessa forma, Felser 
explica por que os verbos de percepção com interpretação direta não admitem a presença de PILs: considerando-se que a interpretação direta do verbo de percepção é analisada como resultado do controle obrigatório que o argumento Evento da matriz exerce sobre o argumento Evento da subordinada, o PSL é o único tipo de predicado possível nessas construções. Desse controle resulta igualmente a dependência temporal da subordinada com relação à matriz. A diferença aspectual observada entre os complementos infinitivos e os complementos gerundivos é explicada pela presença dos traços aspectuais diferentes em Asp - [+prog] no caso do gerúndio e [-prog] no caso do infinitivo.

Como especificamos na introdução deste trabalho, concordamos com Felser que distinção entre PILs e PSLs deve ser realizada em termos de uma diferença na estrutura argumental desses predicados: os PSLs possuem um argumento espaço-temporal ausente dos PILs. Propomos igualmente que a estrutura dos complementos não finitos dos verbos de percepção em PB é uma projeção de $\mathrm{Asp}^{4}$. Não adotamos, no entanto, a análise de Felser para explicar os dados do PB. Discutiremos a seguir alguns pontos dessa análise que julgamos problemáticos, a saber, a hipótese de que o infinitivo denota um aspecto perfectivo, a estipulação de que somente os PSLs projetam AspP e a análise de controle de evento.

\subsection{Ospecto dos complementos infinitivos e gerundivos}

Não concordamos com Felser com relação à hipótese de que o infinitivo denota um aspecto perfectivo. Acreditamos que os complementos gerundivos, por serem marcados pela morfologia - ndo, apresentam de fato um aspecto "progressivo", mas que os complementos infinitivos, que não portam marca morfológica aspectual, não seriam especificados para o aspecto. Não estamos afirmando que esse tipo de complemento não denota aspecto, mas que seu aspecto não é determinado pela forma infinitiva. Sugerimos que o aspecto dos complementos infinitivos é dependente do aspecto do verbo de percepção, da mesma forma que o tempo nessas construções é dependente do tempo da matriz.

É importante especificarmos o que entendemos como aspecto "progressivo" dos complementos gerundivos. Tradicionalmente, vários sentidos são atribuídos à forma do progressivo (-ing em inglês, -ndo em 
português), como o sentido de duração, de uma ação em progresso ou de uma ação incompleta (Binnick, 1991). De forma geral, os autores concordam que o sentido da forma do progressivo corresponde ao valor aspectual imperfectivo. Essa é a posição, por exemplo, de Wachowicz (2003), que analisa a forma progressiva do PB construída com o verbo estar mais um verbo no gerúndio do ponto de vista da abordagem composicional de Verkuyl (1993, 1999). Para a autora, a morfologia - ndo do verbo principal na perífrase do progressivo é responsável pela leitura durativa obtida. Além do valor imperfectivo, considerado sob uma perspectiva qualitativa do aspecto, ela especifica que a leitura aspectual do progressivo pode apresentar ainda, de uma perspectiva quantitativa, os valores episódico, iterativo e habitual.

Sem aprofundar essa discussão, nós assumiremos que o valor aspectual da forma do progressivo pode ser identificado ao imperfectivo. $\mathrm{O}$ que nos interessa neste trabalho não é definir precisamente o valor aspectual da forma progressiva, mas compreender que essa forma possui um valor aspectual qualitativo intrínseco, ao qual nos referiremos indistintamente como "progressivo", "imperfectivo" ou "durativo". Com relação aos complementos gerundivos dos verbos de percepção, assumiremos que, devido à morfologia -ndo, eles denotam o valor aspectual imperfectivo característico da forma do progressivo.

O objetivo principal dessa discussão é a comparação entre os valores aspectuais apresentados pelos complementos infinitivos e gerundivos do $\mathrm{PB}$. Conforme visto anteriormente, Felser afirma que o complemento gerundivo denota um aspecto imperfectivo, enquanto o complemento infinitivo denota um aspecto perfectivo. Contrariamente a Felser, argumentamos que o aspecto do complemento infinitivo não está ligado à forma infinitiva, mas ao aspecto do verbo de percepção. Em nossa opinião, somente o aspecto do complemento gerundivo está ligado à forma do verbo encaixado.

Com o objetivo de apoiar essa hipótese, contrastemos os exemplos em (10) e em (11) do PB, que se distinguem unicamente com relação ao aspecto do verbo de percepção, perfectivo em (10) e imperfectivo - ou "progressivo" - em (11).

(10) a Eu vi [a Maria se afogando], mas alguém a salvou.

b \#Eu vi [a Maria se afogar], mas alguém a salvou. 
(11) a Eu estava vendo [a Maria se afogando], mas alguém a salvou.

b Eu estava vendo [a Maria se afogar], mas alguém a salvou.

Ao examinarmos as construções em (10), paralelas às construções do inglês dadas em (5), podemos afirmar, como o fez Felser a respeito das sentenças em (5), que o complemento infinitivo em (10b) torna a frase incoerente, pois ele implica uma ação considerada em sua totalidade, enquanto o complemento gerundivo em (10a) torna a frase coerente, visto seu aspecto imperfectivo. A diferença com relação à análise de Felser reside no fato de considerarmos que o aspecto perfectivo do infinitivo em (10b) não é resultado de um traço [-prog] associado à forma infinitiva, mas sim da dependência aspectual do infinitivo com relação ao verbo de percepção, que aparece em uma forma que exprime o aspecto perfectivo.

Quando examinamos os exemplos em (11), em que o verbo de percepção apresenta um aspecto imperfectivo, constatamos que a incoerência observada em (10) desaparece. A situação descrita pelo complemento infinitivo (11b) não é mais vista em sua totalidade ou sentida como "acabada", podendo dessa forma ser interrompida. Devemos notar que essa percepção da situação descrita pelo complemento infinitivo é compatível com o aspecto denotado pelo verbo de percepção. Como conseqüência, não é fácil apontar a diferença de interpretação entre a sentença em (11a), formada de um complemento gerundivo, e a sentença em (11b), formada de um complemento infinitivo. A comparação entre esses exemplos nos leva a supor que o complemento infinitivo "herda" o aspecto do verbo de percepção. Vale a pena observar que o aspecto do complemento gerundivo, quando avaliado sob o ponto de vista quantitativo, também está ligado ao aspecto do verbo de percepção. Nas construções em (12), por exemplo, o valor episódico (12a) ou iterativo (12b) do evento denotado pelo complemento gerundivo corresponde ao valor do evento da percepção. Nos dois casos, entretanto, o complemento gerundivo apresenta um aspecto imperfectivo.

(12) a Maria viu Antônio correndo na praia.

b Maria tem visto Antônio correndo na praia.

Em resumo, acreditamos que os complementos infinitivos e os complementos gerundivos se distinguem com relação ao aspecto, no sentido 
de que, para os complementos gerundivos, o aspecto é especificado como "progressivo", devido à morfologia -ndo do verbo, enquanto para os complementos infinitivos, o aspecto não é especificado; o infinitivo assume o valor aspectual do verbo de percepção. O que queremos ressaltar com essa discussão é que, enquanto o aspecto imperfectivo dos complementos gerundivos está ligado à forma desse complemento, o aspecto dos complementos infinitivos é dependente do aspecto do verbo de percepção. Na seção 3, em que tratamos da estrutura temporal da frase, examinaremos com maiores detalhes a questão do aspecto dos complementos infinitivos e gerundivos.

\subsection{A projeção de AspP}

Uma outra questão a ser avaliada na proposta de Felser é a estipulação de que os PILs não projetam AspP, baseada na impossibilidade de esses predicados assumirem a forma progressiva. Essa proposta não contempla, por exemplo, dados do tipo dos que aparecem em (13), com um PIL no gerúndio.

(13) a I just can't see [John owning a mansion]. (FELSER, 1999, p. 80.)

b Eu não consigo ver [o João possuindo uma mansão].

Para Felser, o complemento gerundivo em (13a) não é oracional; ela o analisa como um DP complexo, em que o gerúndio é um modificador do nome. Como modificador do nome, um PIL poderia, de acordo com Felser, aparecer sob a forma gerundiva. Ela observa ainda que a interpretação dos verbos de percepção nas frases em (13) não é direta, mas imaginativa - a percepção se passa na imaginação do experienciador. A interpretação das sentenças em (13) é de fato imaginativa, mas não concordamos com Felser quanto à análise do complemento gerundivo como um DP complexo.

Primeiramente, para Boivin (1998), por exemplo, que estudou a complementação do verbo ver com interpretação imaginativa em inglês e em francês, esse tipo de complemento forma um constituinte único cuja estrutura é um TP. Além disso, em Rodrigues (2004, 2006), mostramos que esse tipo de complemento em PB (13b) deve ser analisado como um constituinte oracional. Dessa forma, a estipulação de Felser sobre a projeção ou não de 
AspP segundo o tipo de predicado do complemento perde sua motivação: por que razão um PIL, ao contrário de um PSL, não projetaria AspP, visto que pode aparecer na forma gerundiva em uma oração, como ilustrado em (13)? Parece-nos que o principal problema de sua análise está ligado à realização sintática proposta para esses predicados.

Ao contrário de Felser, propomos que AspP sempre é projetado na estrutura dos complementos não finitos, independentemente do tipo do predicado. Justificaremos nossa proposição com base na proposição de Ramchand (2004) para a estrutura temporal da sentença, que examinaremos na seção 3. Quanto à distinção entre PILs e PSLs, assumimos, neste trabalho, que ela é gramatical e adotamos a proposta de Kratzer (1995) de que os PSLs apresentam um argumento espaço-temporal que está ausente dos PILs.

\subsection{A dependência temporal dos complementos não finitos}

Examinemos agora a explicação de Felser com relação à dependência temporal dos complementos não finitos dos verbos de percepção. Em sua análise, essa dependência aparece como resultado do controle exercido pelo argumento Evento da matriz sobre o argumento Evento da subordinada. Em uma crítica à análise de Felser, Basilico (2003) afirma que a simultaneidade temporal entre o evento da percepção e o evento percebido não significa necessariamente que o evento da subordinada seja controlado pelo evento da matriz. No caso dos verbos de controle, como prometer, o controlador e o controlado possuem a mesma referência. Essa noção de controle aplicada à análise de Felser leva à conclusão de que o evento da matriz pode ser identificado ao evento da subordinada, o que não é desejável, pois o evento da percepção é distinto do evento percebido, apesar de ocorrerem simultaneamente. Para sustentar a noção de que nas construções perceptivas ocorrem dois eventos distintos, Basilico fornece o exemplo em (14), que mostra claramente diferentes localizações para os dois eventos.

(14) a While sitting in my office, I saw the car hit the pedestrian in the street.

Concordamos com Basilico e rejeitamos, assim, a proposta de Felser de que a dependência temporal dos complementos não finitos dos verbos de 
percepção está ligada a um controle exercido pelo evento da matriz sobre o evento da subordinada. Acreditamos que a presença ou ausência do argumento evento nos predicados desses complementos não é o único fator a ser levado em conta na determinação da estrutura temporal da oração. $\mathrm{Na}$ seção que segue, discutiremos essa estrutura com maiores detalhes.

\section{A ESTRUTURA TEMPORAL DA SENTENÇA}

Examinaremos, nesta seção, a proposta de Ramchand (2004) para representação temporal da sentença, fundamentada no sistema de Reichenbach (1947), em que o tempo exprime uma relação entre três pontos, o ponto $\mathrm{E}$ (tempo do evento), o ponto $\mathrm{S}$ (tempo da enunciação) e o ponto $\mathrm{R}$ (tempo de referência). Com base em trabalhos recentes que adotam o sistema reichenbacheano, como os de Giorgi e Pianesi (1997) e Demirdache e UribeEtxebarria (2000), Ramchand propõe que o Aspecto da sentença está associado à relação entre os pontos $\mathrm{E}$ e $\mathrm{R}$, enquanto o Tempo, por sua vez, especifica a relação entre os pontos $\mathrm{S}$ e $\mathrm{R}$, localizando o tempo de referência com relação ao tempo de enunciação.

De forma geral, para Ramchand, o domínio temporal envolve um conjunto de projeções ordenadas hierarquicamente. A primeira projeção, que engloba o domínio da estrutura do evento $(v \mathrm{P})$, corresponde a AspP e está ligada ao aspecto do predicado (ou inner aspect, que descreve a estrutura temporal interna do evento). A última projeção do domínio temporal - TP - expressa a relação entre o tempo de referência e o tempo de enunciação. Núcleos Asp intermediários podem modificar o núcleo Asp ligado ao aspecto do predicado, contribuindo dessa forma para a determinação do aspecto sintático (outer aspect). Esses núcleos seriam responsáveis por modificações aspectuais relativas à iteratividade, habitualidade ou progressividade.

Ramchand afirma que a composição aspectual da sentença é complexa, compreendendo, na verdade, tanto noções sobre a estrutura do evento quanto noções temporais, e, por isso, a composição do aspecto deve ser calculada em diferentes níveis. Ramchand propõe que a composição do aspecto no nível do predicado (a interpretação do verbo com sua estrutura argumental) possui uma "primeira fase", também composicional, que não é temporal. Não entraremos em detalhes sobre o tratamento dado por Ramchand ao que ela chama de "primeira fase" da composição do aspecto. 
O que nos interessa em seu sistema é sua proposição a respeito da estrutura temporal da frase, mais especificamente, o papel do aspecto nessa estrutura.

Em seu sistema, o ponto E é representado por uma variável eventiva (e não temporal, como normalmente proposto em outras abordagens que utilizam as relações entre os pontos de Reichenbach para dar conta da semântica temporal da frase), resultado do cálculo realizado na "primeira fase" (não temporal) da composição do aspecto. O ponto R é representado por uma variável temporal referencial $t$, introduzida pelo núcleo Asp, que localiza o evento temporalmente. As diferentes relações existentes entre E e R são especificadas por diferentes valores associados à variável $t$ em Asp. O tempo de referência é nomeado por Ramchand "tempo de asserção" e definido como o tempo para o qual uma asserção é realizada. Formalmente, a relação entre o evento e a variável temporal é estabelecida por uma função que realiza o mapeamento entre um evento e a linha temporal que ele ocupa.

Ramchand afirma que a composição da estrutura de evento é complexa e argumenta que seu sistema permite explicar as diversas formas de estabelecer o aspecto da sentença, dado que os diferentes aspectos do predicado podem ser representados por diferentes valores em Asp. O núcleo T pode então ligar essa variável e relacioná-la ao tempo de enunciação. Ramchand (2004, p. 333) afirma:

Assuming that $\mathrm{vP}$ denotes some predicate over events, the aspectual head combines with it to bind the event variable, introduce $t$, and to specify the relationship between the two. The actual relationship specified will depend on the particular Asp head. The general property of the Asp head, therefore, is to bind the event variable, and create a predicate over times that are somehow related to that event. The particular content of the Asp head will vary, ranging from very specific conditions on the relation between the time variable and the event, to a very simple minimal condition. [...] Further up the clause, in a completely parallel way, the tense head combines with a predicate over times to bind that time variable and relate it (anchor it) to the speech time in a particular way. ${ }^{5}$ 


\section{O ARGUMENTO ESPAÇO-TEMPORAL}

Nesta seção, discutiremos a relação entre o argumento espaço-temporal dos PSLs e o tempo da sentença. Apesar de não desenvolvermos uma análise completa da estrutura temporal das construções perceptivas nem uma implementação sintática precisa das nossas proposições, acreditamos que essas proposições apontam para uma possível solução das questões colocadas nesse trabalho.

Fernald (2000), assumindo a proposição de Kratzer (1995) de que os PSLs apresentam um tipo de argumento - um argumento espaço-temporal - que está ausente dos PILs, sugere que a parte temporal desse argumento é preenchida pelo tempo do evento de Reichenbach, representado pelo ponto E. Vimos que Ramchand (2004) associa o ponto E a uma variável eventiva, resultado de um cálculo complexo no domínio da estrutura de evento $(v \mathrm{P})$. É importante estabelecer aqui uma distinção entre o argumento espaçotemporal do verbo e a variável que representa o evento no sistema de Ramchand. Consideramos que o valor da variável eventiva é resultado de um cálculo que inclui, entre outros elementos, os argumentos do verbo, inclusive o argumento espaço-temporal, quando presente. Assim, ainda que o argumento espaço-temporal tenha um papel importante na determinação do valor da variável eventiva, ele não é o único elemento a participar do cálculo da composição do evento. Supomos então que, mesmo que o predicado não apresente o argumento espaço-temporal, um valor é atribuído à variável eventiva.

Não faz parte dos objetivos deste trabalho propor uma análise para especificar o papel preciso do argumento espaço-temporal no valor assumido pela variável eventiva dos predicados complementos de um verbo de percepção. Supomos apenas que esse papel é relevante e que o valor da variável eventiva deve, em princípio, ser diferente conforme o predicado seja um PIL ou um PSL, visto que, devido à presença ou ausência do argumento espaço-temporal, suas estruturas argumentais são fundamentalmente diferentes. Conseqüentemente, o valor da variável temporal referencial introduzida por Asp deve ser igualmente diferente, conforme o predicado seja formado por um PSL ou por um PIL. Essa diferença deve refletir, por exemplo, o fato de que os PSLs, contrariamente aos PILs, apresentam 
propriedades dêiticas e anafóricas. Fernald (2000), como vimos, explica esse fato propondo que os PILs, diferentemente dos PSLs, não possuem um tempo de evento e que a parte temporal do argumento espaço-temporal dos PSL é o tempo do evento de Reichenbach. Fundamentalmente, nossa proposição não é contrária à proposição de Fernald, visto que as duas consideram a diferença entre PSLs e PILs com relação à ligação desses predicados com o tempo do evento.

Vimos que Ramchand (2004) sugere que outros núcleos aspectuais intermediários podem estar presentes na frase e, dessa forma, contribuir à determinação do aspecto gramatical. Assumimos assim, na estrutura da sentença, uma projeção aspectual que explica o aspecto do predicado e outras possíveis projeções, interagindo com ela para dar conta do aspecto gramatical (no caso, por exemplo, do valor progressivo). No entanto, para simplificar a exposição da argumentação, vamos nos referir a um núcleo Asp, entendendoo como o núcleo aspectual relativo ao aspecto do predicado, que pode ser modificado por um operador.

\section{OS COMPLEMENTOS INFINITIVOS E GERUNDIVOS DO PB}

O exame dos dados do PB referentes à complementação não finita dos verbos de percepção, ilustrados em (15)-(16), revelou-nos que esses complementos apresentam uma dependência temporal com relação à principal (15) e que eles são incompatíveis com PILs (16). Uma comparação entre os complementos gerundivos e os complementos infinitivos em termos do valor aspectual que eles veiculam levou-nos a concluir que o aspecto imperfectivo do complemento gerundivo é determinado no interior do complemento (17), enquanto o aspecto do complemento infinitivo depende do aspecto do verbo de percepção (18). Vimos também que, sob o ponto de vista quantitativo, o aspecto dos complementos gerundivos está ligado ao aspecto do verbo de percepção, como nos mostram os exemplos em (19), nos quais o evento descrito pelo gerúndio é episódico (19a) e iterativo (19b), como os respectivos eventos da percepção.

(15) a *Ontem, eu vi o João beijar a Maria antes de ontem.

b *Ontem, eu vi o João beijando a Maria antes de ontem. 
(16) a *Nós vimos o João saber a lição.

b *Nós vimos o João sabendo a lição.

(17) a Eu vi a Maria se afogando, mas alguém a salvou.

b Eu estava vendo a Maria se afogando, mas alguém a salvou.

(18) a \#Eu vi a Maria se afogar, mas alguém a salvou.

b Eu estava vendo a Maria se afogar, mas alguém a salvou

(19) a Maria viu Antônio correndo na praia.

b Maria tem visto Antônio correndo na praia.

Com o objetivo de explicar essas propriedades, propusemos que a estrutura dos complementos não finitos dos verbos de percepção é formada pela projeção AspP, tanto no caso dos PSLs quanto dos PILs, e argumentamos que a diferença de comportamento observada entre os dois tipos de predicado está relacionada ao valor da variável temporal referencial $t$, introduzida pelo núcleo Asp, que especifica as diferentes relações existentes entre o evento e o tempo de referência da sentença. Esse valor estaria, por sua vez, ligado, entre outros fatores, à presença ou ausência do argumento espaço-temporal nos predicados. Examinemos agora como se daria a interpretação da variável $t$ nas construções perceptivas.

$\mathrm{Na}$ estrutura temporal das sentenças finitas, a variável temporal referencial $t$ é, como proposto por Ramchand (2004), ligada por T e interpretada com relação ao ponto $S$, que pode ser associado ao momento da enunciação ou ao tempo do evento da matriz. No caso dos complementos não finitos dos verbos de percepção, no entanto, T não está presente na estrutura para ligar a variável $t$. Argumentamos que, nesse caso, para que essa variável possa ser interpretada, seu valor deve ser compatível com o valor da variável temporal referencial da matriz.

Defendemos que, na percepção direta, essa compatibilidade é possível no caso dos PSLs, mas impossível no caso dos PILs. Mais especificamente, acreditamos que o valor da variável temporal $t$ associada a um PSL é "específico", no sentido de que ela pode referir-se a um momento determinado na linha de tempo associada ao evento. Essa propriedade tornaria a variável $t$ da subordinada compatível com a variável $t$ da matriz. Por outro lado, consideramos que, no caso dos PILs, o valor da variável temporal $t$ não é "específico", o que a tornaria incompatível com a variável 
$t$ da matriz. Como a identificação entre as variáveis da encaixada e da matriz é impossível, $t$ não pode ser interpretada e a construção com um PIL é agramatical. A diferença entre os valores da variável $t$ apareceria como uma consequiência da presença ou ausência do argumento espaço-temporal no predicado.

Argumentamos que, na ausência de T, a identificação da variável temporal referencial do complemento à variável temporal referencial da matriz determina a simultaneidade entre o evento da percepção e o evento descrito pelo complemento e, conseqüentemente, a leitura direta do verbo de percepção. No caso dos complementos gerundivos, o operador progressivo modifica a variável temporal e o complemento pode denotar o aspecto imperfectivo de forma independente, como ilustrado pelos exemplos em (17) no início desta seção. Outros valores associados à leitura aspectual da forma gerundiva, como os valores episódico e iterativo, dependem do valor do verbo de percepção (19). No caso dos complementos infinitivos, contudo, a ausência de um operador aspectual definindo o aspecto gramatical explica a dependência aspectual do infinitivo com relação ao verbo de percepção (18).

\section{CONSIDERAÇÕES FINAIS}

Este trabalho examinou os complementos infinitivos e gerundivos dos verbos de percepção com interpretação direta com o objetivo de explicar algumas de suas propriedades ligadas ao tempo e ao aspecto.

Acreditamos que as hipóteses aqui levantadas vão, de forma geral, ao encontro das intuições de alguns pesquisadores com relação ao comportamento dos PSLs e PILs. Por exemplo, Boivin (1998) sugere que os PILs devem ser interpretados relativamente a Te Fernald (2000) sugere que o argumento espaço-temporal dos PSLé utilizado por meio de uma operação de indexação e não ligado por um operador. Essas hipóteses privilegiam ainda o tratamento composicional do aspecto, o que possibilitaria um tratamento mais "flexível” da distinção entre PSLs e PILs. A separação entre as variáveis eventiva e temporal proposta por Ramchand (2004) permite, em nossa opinião, uma melhor compreensão da relação entre a estrutura temporal da sentença e a estrutura do evento. Além disso, esperamos que este trabalho tenha mostrado a necessidade de estudos mais aprofundados sobre as interações aspectuais nas construções com small-clauses verbais. 


\section{NOTAS}

${ }^{1}$ A classe de verbos de percepção não-agentivos - ver, ouvir, sentir - é definida em função do papel passivo que possui o sujeito desses verbos na percepção e opõe-se à classe dos verbos de percepção agentivos, como olhar, cujo sujeito possui um papel ativo.

${ }^{2}$ Em trabalhos anteriores (RODRIGUES, 2002, 2003, 2006), mostramos que, em $\mathrm{PB}$, o complemento infinitivo forma um constituinte único complemento do verbo de percepção e que o complemento gerundivo é ambíguo, podendo receber três análises diferentes: i) um constituinte de tipo DP complexo, em que o gerúndio é um modificador do nome; ii) dois constituintes distintos - um DP objeto do verbo de percepção seguido de um predicado secundário; e iii) um constituinte único oracional. No presente trabalho, examinaremos apenas a estrutura do complemento gerundivo citada em iii), que corresponde à estrutura dos complementos infinitivos. Nessa estrutura, o DP que segue o verbo de percepção é sujeito do verbo encaixado. Vale a pena lembrar que, em PB, os complementos infinitivos podem ser construídos tanto com o infinitivo flexionado quanto com o infinitivo não flexionado. Nos dois casos, analisamos o complemento infinitivo como um constituinte único.

${ }^{3}$ A interpretação direta do verbo de percepção, resultado de contato direto entre o experienciador da percepção e aquilo que é percebido, é geralmente estudada em oposição à percepção indireta, obtida em presença de complementos finitos (i), em que o contato direto não é necessário.

(i) Eu vi que você rasgou o jornal.

${ }^{4}$ Os complementos infinitivos apresentam muito provavelmente uma estrutura diferente da estrutura dos complementos gerundivos, devido à possibilidade de serem formados com um infinitivo flexionado. Nos complementos infinitivos flexionados, o caso nominativo do sujeito do infinitivo deve ser verificado no interior do complemento. Em Rodrigues (2006), seguindo a proposição de Pires (2001) para a estrutura das construções infinitivas em PB, sugerimos que os complementos infinitivos projetam TP, com traços phi completos, no caso do infinitivo flexionado, e incompletos, no caso do infinitivo não flexionado. Com base nos estudos de Gonçalves (1999), propomos que TP nesses casos é temporalmente inerte. Optamos, neste trabalho, por tratar os complementos infinitivos e gerundivos da mesma forma, como projeções de Asp, por entender que a presença de TP vazio de traços temporais não altera o tratamento que propomos para explicar as propriedades temporais e aspectuais estudadas. 
5 "Assumindo-se que $v P$ denota um predicado sobre eventos, o núcleo aspectual associa-se a $v P$ para ligar a variável eventiva, introduzir $t$ e especificar a relação entre essas duas variáveis. A relação especificada dependerá do valor associado ao núcleo Asp. A propriedade geral do núcleo Asp é, dessa forma, ligar a variável eventiva e criar um predicado sobre tempos relacionados ao evento. O conteúdo do núcleo Asp será variável, expressando desde condições bem específicas definindo a relação entre a variável temporal e o evento até uma simples condição mínima. [...] De uma forma paralela, em uma posição mais alta da sentença, $T$ associa-se a um predicado sobre tempos para ligar a variável temporal e relacionála (ancorá-la) ao tempo da enunciação de forma particular."

\section{REFERÊNCIAS}

BASILICO, D. The topic of small clauses. Linguistic Inquiry, Cambridge, Mass., v.34, n. 1, p.1-35, 2003.

BINNICK, R. Time and the verb: a guide to tense and aspect. New York: Oxford University Press, 1991.

BOIVIN, M. C. Complementation and interpretation: the concrete and imaginative readings of 'visual' perception verbs. MIT Working Papers in Linguistics, Cambridge, MA., v. 25, p. 103-123, 1998.

DECLERCK, R. On the role of progressive aspect in nonfinite perception verb complements. Glossa, Burnaby, v. 15, p. 83-114, 1981.

DEMIRDACHE, H; URIBE-ETXEBARRIA, M. The primitives of temporal relations. In: MARTIN, R.; MICHAELS, D.; URIAGEREKA, J. (Org.). Step by step: Essays on minimalist syntax in honor of Howard Lasnik. Cambridge, MA: MIT Press, 2000. p. 157-187.

FELSER, C. Verbal complement clauses. Amsterdam/Philadelphia: John Benjamins Publishing Company, 1999.

FERNALD, T. B. Predicates and temporal arguments. New York/Oxford: Oxford University Press, 2000.

GIORGI, A.; PIANESI, F. Tense and aspect: from semantics to morphosyntax. New York/Oxford: Oxford University Press, 1997. 
GONÇALVES, A. P. L. Predicados complexos verbais em contextos de infinitivo não preposicionado do Português Europeu. 1999. Tese (Doutorado) Universidade de Lisboa, Lisboa.

KRATZER, A. Stage-level and individual-level predicates. In: CARLSON, G.; PELLETIER, F. (Org.). The generic book. Chicago: University of Chicago Press, 1995. p. 125-175.

PIRES, A. The syntax of gerunds and infinitives: subjects, case and control. 2001. Tese (Doutorado) - Universidade de Maryland, Maryland.

RAMCHAND, G. C. Time and the event: the semantics of Russian Prefixes. In : SVENONIUS, P. (Org.). Nordlyd 32: Slavic Prefixes. Troms $Æ$ : Université de TromsÆ, 2004. p. 323-361. (Disponível no site http://www.ub.uit.no/munin/ nordlyd)

REICHENBACH, H. Elements of Symbolic Logic. New York: Free Press, 1947.

RODRIGUES, P. Le gérondif comme complément des verbes de perception dans le portugais brésilien. Revista Letras, n. 57, p. 271-292, 2002.

. O gerúndio e os verbos de percepção visual no português brasileiro. Estudos Lingüísticos, n. 32, 2003.

. O status de Small Clause das construções gerundivas e adjetivais complementos de verbos de percepção com interpretação imaginativa. VI Encontro do CELSUL, Florianópolis, 2004.

. Les compléments infinitifs et gérondifs des verbes de perception en portugais brésilien. 2006. Tese (Doutorado) - Université du Québec à Montréal, Montreal.

VERKUYL, H. A theory of aspectuality - the interpretation between temporal and atemporal structure. Cambridge: Cambridge University Press, 1993.

VERKUYL, H. Aspectual issues - studies on time and quantity. Stanford: CSLI Publications, 1999.

WACHOWICZ, T. C. As leituras aspectuais da forma do progressivo do Português Brasileiro. 2003. Tese (Doutorado) - Universidade de São Paulo, São Paulo. 